4th National Seminar on Guidance and Counseling (SNBK 2019) and Workshop on

Pedagogical Theory and Practice (WTPP 2019)

SHEs: Conference Series 2 (2) (2019) 40 - 46

\title{
Assessment of Hanoman's Character Value (Indigenous) as a Counselor Competence for Industrial Revolution
}

\author{
Maya Tsuroya Alfadla ${ }^{1}$, Putri Laras Trisnawati ${ }^{2}$ \\ Program Studi Pascasarjana Bimbingan dan Konseling Universitas Negeri Malang \\ mayatsuroya@gmail.com ${ }^{1}$, putrilarastr@gmail.com²
}

\section{Article History}

accepted 01/11/2019

approved 11/11/2019

published 31/12/2019

\begin{abstract}
Industrial Revolution 4.0 provides changes in digitalization and automation for various sectors in Indonesia. These changes have an impact on the Guidance and Counseling profession can be replaced by the role of robots and online counseling. This study will discuss how the Guidance and Counseling profession responds to the challenges by strengthening the competency of counselors through the analysis of Hanoman's character values as the character of indigenous counselors. Hanoman is a puppet character who has a face and body shape that resembles an ape but has a kind heart, is willing to sacrifice and responsibility. The developed Hanoman character is empathy, unconditional acceptance, dynamic, genuine, real self to be one step to strengthen the competence of indigenous counselors in the era of the industrial revolution. This strengthening aims to provide a unique Indonesian character in competing with the changes that occur.
\end{abstract}

Keywords: Industrial Revolution, Counselor Competence, Hanoman's Character Value

\begin{abstract}
Abstrak
Revolusi Industri 4.0 memberikan perubahan digitalisasi dan automatisasi untuk berbagai sektor di Indonesia. Perubahan tersebut memberikan dampak pada profesi Bimbingan dan Konseling dapat digantikan oleh peran robot dan konseling online. Kajian ini akan membahas bagaimana profesi Bimbingan dan Konseling menjawab tantangan dengan menguatkan kompetensi konselor melalui analisis nilai karakter Hanoman sebagai karakter konselor indigenous. Hanoman merupakan tokoh wayang yang memiliki bentuk wajah dan badan menyerupai kera namun memiliki sifat yang baik hati, rela berkorban dan tanggung jawab. Karakter Hanoman yang dikembangkan adalah empati, penerimaan tanpa syarat, dinamis, genuine, real self menjadi salah satu langkah untuk menguatkan kompetensi konselor indigenous di era revolusi industri. Penguatan ini bertujuan untuk memberikan karakter khas Indonesia dalam bersaing dengan perubahan yang terjadi.
\end{abstract}

Kata kunci: Revolusi Industri, Kompetensi Konselor, Nilai Karakter Hanoman

Social, Humanities, and Education Studies (SHEs): Conference Series https://jurnal.uns.ac.id/shes

p-ISSN 2620-9284

e-ISSN 2620-9292 


\section{PENDAHULUAN}

Revolusi Industri 4.0 menerapkan konsep automatisasi yang dilakukan oleh mesin tanpa memerlukan tenaga manusia dalam pengaplikasiannya oleh pelaku industri demi efisiensi waktu, tenaga kerja, dan biaya (Baenanda, 2019). Era revolusi industri 4.0 merupakan keadaan dimana teknologi informasi telah menjadi basis dalam kehidupan manusia. Segala hal menjadi tanpa batas (Borderless) dengan penggunaan daya komputasi dan data yang tidak terbatas (Unlimited) karena dipengaruhi oleh perkembangan internet dan teknologi digital (Ristekdikti, 2018). Internet of Things (IoT) merupakan kemampuan dalam menyambungkan dan memudahkan proses komunikasi antara mesin, perangkat, sensor, dan manusia melalui jaringan internet, hal tersebut berkembang dalam berbagai bidang mulai dari industri, ekonomi, transportasi dan pendidikan (Baenanda, 2019). Menjawab tantangan revolusi industri 4.0 pendidikan Indonesia dirancang dengan mengembangkan pembelajaran berbasis keterampilan belajar dan berinovasi. Keterampilan ini berkenaan dengan kemampuan berfikir kreatif, kemampuan memecahkan masalah, kemampuan berkomunikasi, berkolaborasi dan kemampuan untuk berkreativitas dan berinovasi (Trilling dan Fadel, 2009; 48). Pemanfaatan teknologi informasi juga dikembangkan dalam dunia pendidikan untuk memberikan keterampilan siswa menghadapi era baru.

Digitalisasi pendidikan juga memberikan perubahan terhadap layanan yang diberikan sekolah untuk mempermudah proses pendidikan. Perubahan tersebut salah satunya terdapat dalam layanan konseling yang diberikan oleh konselor ahli atau guru bimbingan dan konseling. Konseling menyediakan kondisi yang mendukung untuk menciptakan lingkungan emosional yang aman agar seorang individu dapat mengeksplorasi masalah pribadi. Ketakutan, kemarahan, pengabaian, penolakan, trauma, dan kebingungan dapat diperiksa dan diklarifikasi dengan menggunakan konseling sebagai cermin yang merefleksikan kembali kebenaran masalah (Martin, 2019). Layanan konseling online banyak dikembangkan di Indonesia sebagai usaha efisiensi waktu, tenaga, biaya dan beberapa keunggulan lainnya. Konseling online salah satunya dikembangkan oleh Universitas Brawijaya sebagai usaha memfasilitasi mahasiswa untuk mencapai kesehatan mental. Platform Konseling lain berbasis aplikasi android dan IOS bernama KALM. Aplikasi tersebut menawarkan jaminan kerahasiaan, keamanan dan biaya yang terjakau untuk penggunanya. Amerika Serikat pada tahun 2014 mengagas penggunaan Robot interaktif /sosial yang digunakan untuk tujuan terapeutik. Robot ini menampilkan perilaku seperti manusia atau memiliki kapasitas interaksi sosial lainnya dan biasa disebut robot bantu sosial (Feil-Seifer \& Mataric, 2005; Tapus, Mataric, \& Scassellati, 2007 dalam David, 2014). Robo Therapist berfungsi sebagai psikoterapis. Robot ini dipilih karena biaya tinggi ketika datang ke terapis, kekurangan penyedia layanan, atau ketidakmampuan psikoterapis untuk merespon klien (David, 2014).

Perubahan tersebut memberikan dampak pada organisasi profesi konselor atau guru bimbingan dan konseling sebagai tenaga ahli yang memfasilatasi proses konseling di sekolah. Perkembangan teknologi bidang konseling tersebut tentu memiliki kekurangan salah satunya adalah interaksi oleh platfrom secara online meminimalkan tatap muka dan mengesampingkan hubungan terapeutik yang diberikan dalam konseling. Hasil konseling dipengaruhi oleh beberapa faktor, salah satu yang memiliki dampak besar dalam hasil konseling adalah sikap konselor. Sikap konselor dapat berupa sikap positif atau reaktif. Sikap termasuk keterampilan yang dapat dipelajari dan dipraktekkan. Sikap konselor terdiri dari: (a) hormat; (2) keaslian/ kongruensi; (3) penerimaan positif tanpa syarat; (4) empati; (5) pengungkapan diri; (6) konfrontasi (Gordon, UNESCO). Hormati konseli dengan menghindari pemaksaan nilai diri konselor. Konselor perlu menghindari penghakiman sehingga konseli dapat menerima masalah dan mengatasinya. Keaslian atau biasa disebut sebagai 
kongruensi. Kongruensi merupakan sikap konselor untuk konsisten atau apa yang dikatakan, dan ditunjukkan. Kondisi ini mencerminkan kejujuran, transparansi, dan kepercayaan konselor terhadap konseli. Elemen ini merupakan dasar untuk hubungan konseling. Penerimaan positif tanpa syarat (kehangatan) adalah menerima kondisi konseli tanpa menghakimi. Empati adalah kemampuan untuk memahami apa yang dialami konseli Anda, dan mengomunikasikan perasaan tersebut. Pengungkapan Diri adalah salah satu sikap yang membantu konseli mengungkapkan sesuatu tentang dirinya. Ini membantu untuk menciptakan rasa saling percaya, dan memahami konseli, sehingga ia merasa bebas dan berbicara secara terbuka. Konfrontasi adalah sikap untuk menunjukkan ketidakkonsistenan antara apa yang dikatakan dan apa yang dilakukan oleh konseli (Gordon, UNESCO).

Konselor diharapkan sigap menjawab tantangan revolusi industri keempat ini. Konselor perlu meningkatkan keterampilan dan kompetensi diri untuk bersaing dengan digitalisasi konseling. Salah satu hal yang tidak dapat diberikan oleh platfrom konseling online adalah keterikatan secara emosional yang diberikan oleh konselor secara langsung. Hal lain yang diabaikan dalam proses konseling online adalah karakteristik sosial budaya yang melatar belakangi perilaku manusia. Perilaku manusia dipengaruhi oleh faktor sosial budaya yang berdampak pada pandangan tentang kesehatan mental, pandangan manusia sehat, konsep diri dan pengambilan keputusan (Washington dalam Katz, 1985).

Salah satu perembangan layanan Bimbingan dan Konseling untuk menguatkan kompetensi konselor adalah mengangkat kekayaan indigenous baik berupa nilai, adat, kebiasaan pribumi. Manusia indigenous, yaitu manusia yang masih memegang teguh "adat sebenar-benarnya adat" sebagai unsur utama kebudayaan. Dalam lintasan waktu, masyarakat indigenous-lah yang paling banyak menerima "penetrasi" peradaban asing, meskipun demikian hanya masyarakat indigenous pula yang tidak pernah berhasil ditaklukkan secara sempurna oleh peradaban apapun yang pernah mencoba untuk menaklukkannya (Hidayat, 2010). Meningkatkan kompetensi konselor beridentitas budaya Indonesia, dikembangkan melalui analisis nilai karakter Hanoman. Hanoman atau Hanumat merupakan salah satu dewa dalam kepercayaan agama Hindu, sekaligus sebagai tokoh protagonis dalam wiracarita Ramayana yang paling terkenal (Suryanto, 2014). Hanoman merupakan salah satu tokoh yang unik karena berwujud seekor kera putih dan memiliki karakter layaknya manusia. Karakter yang dimiliki Hanoman diantaranya: Baik, cerdas, patuh (kepatuhan), bertanggung jawab, rendah hati, memiliki harga diri dan memiliki semangat untuk berjuang. Pengembangan ini ditawarkan untuk memberikan identitas konselor berbasis budaya melalui karakter Hanoman. Identitas ini digunakan menjawab tantangan revolusi industri dengan mempertahankan budaya lokal dan memfasilitasi individu. Oleh karena itu dikembangkan Identitas Konselor Bebasis Nilai Karakter Hanoman Untuk Bersaing di Era Revolusi Industri 4.0.

\section{PEMBAHASAN}

Kompetensi konselor menjadi penting melihat tantangan pada era revolusi industri. Meskipun kenyataan bahwa media, mesin, komputerisasi tidak mampu menggantikan "Kehangatan" yang dimiliki manusia, karena alat tersebut yang hanya bisa berjalan sesuai program yang diatur yang bersifat "Dingin". Namun konselor perlu memastikan "Kehangatan" tersebut betul-betul ada pada karakter konselor. Mendengarkan dengan hati menjadi sulit saat ini dengan banyaknya gangguan gadget, media masa yang seolah menjadi ladang orang lain untuk show up, sehingga sangat menarik untuk dibahas atau menjadi tolak ukur keberhasilan diri seseorang. Sedangkan pada dasarnya mendengarkan aktif ketika Anda "Mendengarkan dengan makna". Pendengar hanya berkata sedikit tetapi menyampaikan empati, penerimaan, 
dan keaslian. Pendengar hanya berbicara untuk mencari tahu apakah mereka telah mendengar atau mengerti dengan benar. Mendengarkan dengan seluruh badan, hati, telinga, mata dan mulut (Perinatal Mental Health Project).

Salah satu jawaban dari pertanyaan ketergunaan konselor di era revolusi industri adalah tentang kompetensi konselor akan erat kaitannya dengan kemampuan berhubungan dengan manusia. Jones (2006) mengatakan kemampuan pertama yang harus dimiliki seseorang ketika berhubungan dengan orang lain adalah Listening and showing understanding. Zeno of Citium mengatakan: "Alasan mengapa kita memiliki dua telinga dan hanya satu mulut adalah agar kita dapat mendengarkan lebih banyak dan berbicara lebih sedikit. Mendengarkan adalah salah satu penghargaan paling tinggi yang diberikan profesi helper kepada konselinya. Kadang-kadang tidak didengarkan dapat menimbulkan rasa sakit psikologis ringan; sering tidak didengarkan, rasa sakit sedang; dan kebanyakan tidak didengarkan, rasa sakit yang hebat. Tidak pernah didengarkan akan menjadi seperti hukuman mati psikologis (Jones, 2004: 36). Mendengar akan berbeda dengan mendengarkan. Mendengar melibatkan kapasitas menerima dan menyadari suara sedangkan mendengarkan tidak hanya menerima dan menyadari suara melainkan perlu memahami secara akurat makna yang disampaikan lawan bicara. Mendengarkan orang lain menjadi lebih mudah jika kita juga melatihkan diri untuk mendengarkan batin kita sendiri, seperti pernyataan Jones yang dalam (2004: 37) Indeed the quality of your inner listening, or being appropriately sensitive to your own thoughts and feelings, may be vital to the quality of your outer listening.

Menggali nilai-nilai kearifan lokal sebagai solusi melihat kekayaan barat dan teknologi yang semakin menggerus falsafah Negara. Ini disebut dengan teori indigenous mencakup unsur-unsur spiritual, emosi, mental dan fisik manusia yang menjadi satu kesatuan utuh yang diakui keberadaannya pada masa lalu, masa sekarang, dan untuk masa yang akan datang (Absolon, 2010). Manusia indigenous (di manapun berada) memiliki kepercayaan yang kuat yang bersumber dari tradisi turuntemurun mereka (Sue \& Sue, 2008). Seperti halnya dalam kajian Dakwah Transformatif Melalui Konseling: Potret Kualitas Kepribadian Konselor Perspektif Konseling At-Tawazun Arifin \& Zaini (2014: 144-149) bahwa konselor hendaknya memiliki sikap yang Alim, Kasih sayang (Rahmah), Sabar, Wara' dan Zuhud, Ikhlas dan Tawadhu' dan Pandai Berkomunikasi. Dilihat dari perspektif kualitas kepribadian konselor, konseling at-tawazun cenderung mendekati teori Person Centered Therapy. Pandangan pesantren menyebutkan bahwa untuk mengubah seseoang maka orang yang mengubah itulah yang pertama kali harus bersedia berubah. Selain kemampuan mendengarkan dan komunikasi menjadi model adalah cara yang tepat untuk "mengobati" konseli. Selain itu kajian Karakter Ideal Konselor Multibudaya Berdasarkan Nilai Luhur Semar (Setyaputri: 2017) menyatakan bahwa sikap ideal konselor dapat tergambar dari sosok semar yang (1) religius; (2) netral; (3) toleransi; (4) tulus; (5) disiplin; (6) peduli sosial; (7) bersahabat; (8) adil; (9) jujur; (10) luwes; (11) demokratis; dan (12) rasa ingin tahu. Dari hasil kajian nilai konselor indigenous dapat disimpulkan bahwa pribumi memiliki ragam tauladan sikap yang sekiranya mampu mempertahankan profesi ini sebagai suatu konsep utuh konselor yang dapat memberikan pelayanan konseling, memiliki kompetensi dasar mendengarkann yang baik, penuh penerimaan, berempati, hangat, dan apa adanya. Tentu keutuhan tersebut tidak mampu didapat oleh robot sekalipun.

Kajian ini akan melihat nilai sikap Hanoman yang cocok digunakan sebagai nilai diri konselor indiguntuk mempertahankan budaya lokal. Tokoh Hanoman (हहहहहहह;) atau orang jawa biasa menyebutnya Anoman, merupakan salah satu dewa dalam kepercayaan agama Hindu. Hanoman atau Anoman ini berwujud kera putih, meskipun berwujud kera putih, Anoman memiliki karakter terpuji layaknya manusia. Beberapa 
karakter tersebut diantaranya : Baik, cerdas, bertanggung jawab, rendah hati, memiliki harga diri dan memiliki semangat untuk berjuang. Karakter-karakter yang ada pada diri Hanoman tersebut sesuai memiliki kesamaan dengan hakikat manusia pada pendekatan konseling Humanistik yang mana dalam pendekatan konseling tersebut memandang bahwa pada dasarnya manusia itu baik, makhluk yang dapat dipercaya, cerdas, mampu membuat perubahan yang konstruktif dan mampu menjalani kehidupan yang efektif serta produktif (Corey, 2017).

Meskipun Anoman memiliki perawakan yang gagah, menyeramkan namun Anoman memiliki sisi-sisi yang lembut dan menenangkan. Berikut nilai konselor yang dapat dilihat dari nilai diri Anoman.

\section{Wujud Diri/Real Self}

Konselor hendaknya menemukan siapa dirinya sebagai seorang yang utuh dan bebas dari bayang-bayang kehidupan masa lalu dan masa depan yang berlebihan. Wujud diri Anoman dapat dianalisis melalui rangkuman cerita Alengka Diobong berikut (Pendit, 2015) "Hanoman menjadi tangan kanan kepercayaan Rama untuk membantu menemukan Sita yang diculik Rahwana di kerajaan alengka, dalam misinya menyelamatkan Sita, Hanoman menggunakan berbagai strategi mulai dari menyamar hingga menganalisis keadaan, hal tersebut dilakukan Hanoman untuk membalas budi kepada Rama dengan melakukan amanah yang diberikan dengan baik" hal tersebut menujukkan karakter-karakter baik Hanoman sebagai real self yang dimilikinya. Hanoman memandang dirinya sebagai orang yang mampu menyelesaikan setiap tantangan yang diberikan, tanggung jawab, dapat menyusun strategi dengan baik dan rela berkorban untuk orang lain.

\section{Menerima Tanpa Syarat/ Unconditional Positive Regard}

Menerima tanpa syarat tanpa kecurigaan dan sikap tersebut tidak dibuat-buat dan asli dari hati Hanoman yang disampaikan pada kata-katanya yang sopan. Menurut Farber\&Doolin dalam Corey (2017) Unconditional Positive Regard dapat dicapai melalui identifikasi empatik dengan konseli. Kepedulian itu tidak bersifat posesif dan tidak terkontaminasi oleh evaluasi atau penilaian perasaan, pikiran, dan perilaku konseli sebagai baik atau buruk. Konselor menghargai dan dengan hangat menerima konseli tanpa syarat. Konselor menghargai konseli sebagaimana dirinya dengan pengalaman dan perasaannya. Sikap menerima tanpa syarat ditujukkan dalam cerita Hanoman Diobong (Pendit, 2015) "Rama datang untuk menemui Sugriwa pimpinan para wanara dengan menaiki bukit daerah kekuasaan para wanara, namun kedatangannya mencurigakan, Hanoman diutus Sugriwa untuk memeriksa, Hanoman menemui Rama dan adiknya dengan tutur bahasa halus dan gerak tubuh yang sopan membuat Rama terkesima. Oleh karena kesopanan Hanoman, Rama merasa diterima dengan baik untuk meminta bantuan kepada Sugriwa". Hanoman memberikan sambutan hangat penuh dengan kesopanan. Rama pun merasa diterima dengan ucapan dan sopan santun Hanoman (Suhardi \& Wisdu Subagiyo, 1997).

3. Empati dan Berhati Lembut

Hanoman memiliki karakter empati dan berhati lembut, ini ditunjukkan ketika Hanoman diutus Rama menemui Dewi Sita Hanoman menyaksikan kesetiaan Sita saat menolak rayuan Rahwana dan terharu melihat keberanian Sita pada Rahwana. Kutipan pembicaraan Hanoman dan Dewi Sita di Taman Asokawana tempat Rahwana mengurung Dewi Sita (dalam Pendit,Nyoman S, hal.277:2015) Sita bertanya "Mengapa engkau yakin bahwa aku ini Sinta yang engkau cari?" Hanoman menjawab dengan tenang "Aku melihat saat tuanku melemparkan sehelai rumput ke arah Rahwana. Aku melihat bagaimana dengan berani Tuanku menolak dan mengancam Rahwana. Sikap Tuanku yang tegas merupakan bukti kesetiaan kepada Rama yang patut diteladani setiap perempuan". Hanoman tertunduk, berusaha menyembunyikan air mata 
harusnya yang nyaris menetes. Menjadi empatik berarti memasuki dunia orang lain tanpa dipengaruhi oleh pandangan dan nilai-nilai seseorang sendiri (Freire, 2007; Rogers, 1975) dalam (Sharft, 2012: 217). Untuk melakukannya, individu harus memiliki keterpisahan yang memadai sehingga mereka tidak tersesat di dunia perseptual orang lain (Sharf, 2012: 217).

\section{Genuine}

Keaslian dan kesuaian sikap Hanoman antara apa yang difikirkan, dikatakan dan dilakukan dalam Person Center Therapy dikenal istilah Genuine, sikap ini menyiratkan bahwa konselor itu "hadir" yaitu, mereka asli, terintegrasi, dan otentik. Peran konselor dikembangkan berdasarkan nilai karakter Hanoman hendaknya memunculkan sikap genuine yaitu dengan berperilaku yang asli dan adanya kesesuaian antara fikiran, perasaan dan perilaku dalam proses konseling. Sikap genuine dalam proses konseling dapat memberikan rasa penerimaan terhadap konseli serta menciptakan kondisi fasilitatif untuk membantu mengembangkan potensi diri konseli. Sikap asli ini tergambar saat Anoman menawarkan bantuan kepada Rama dan Laksmana, sampaisampai pantulan ketulusan tersebut dirasakan oleh keduanya. Sambil mengucap sanjungan atas perilaku asli dan tulus yang dimiliki Anoman. "Meski berbusana pertapa, tubuh Tuanku tegak perkasa. Dari diri kalian terpancar kesaktian dan kekuatan yang mampu melindungi kami dan seisi jagad ini. Walau begitu, jika Tuanku meminta, kami akan mengulurkan tangan untuk membantu". Mendengar ucapan selamat datang yang santun dari Hanoman, mereka merasa diterima dengan baik. Sikap dan caranya berbicara memperlihatkan betapa Hanoman mengerti betul akan tugasnya.

\section{Dinamis}

Hal tersebut membuktikan bahwa Hanoman adalah pribadi yang dinamis dalam menghadapi perubahan dan terus memaksimalkan potensinya dalam mencapai tujuannya. Pendit (2015) menggambarkan sikap dinamis dan mau berkembang melalu cerita berikut "Hanoman dalam melakukan misi penyelamatan Sita mengubah dirinya menjadi kera kecil seukuran kucing sehingga dapat menganalisis keadaan lingkungan dan melancarkan aksinya pada malam hari, namun suatu saat Hanoman ditanya dan dipukul oleh salah seorang penjaga dan membuat Hanoman melakukan perlawanan dan harus menganti strateginya untuk menemukan Sita di kerajaan alengka".

\section{SIMPULAN}

Revolusi industri 4.0 memberikan perubahan siginifikan pada berbagai sektor termasuk pendidikan. Digitalisasi membuat profesi konselor dipertanyakan kebergunaannya. Konselor sebagai profesi helper perlu menjawab tantangan zaman dengan meningkatkan kompetensi diri berbasis budaya lokal/Indigenous sebagai identitas. Kehangatan, penerimaan dan dukungan secara emosional masih menjadi keunggulan konselor dalam melakukan konseling tatap muka. Pengembangan karakter Hanoman sebagai usaha membentuk kembali kompetensi konselor di era revolusi industri 4.0. Karakter Hanoman yang dikembangkan menjadi identitas konselor adalah empati, penerimaan tanpa syarat, dinamis, genuine, real self. Karakter ini memiliki kelebihan untuk mengangkat karakter lokal sebagai warisan budaya sebagai identitas konselor Indonesia seutuhnya. Karakter konselor berbasis nilai Hanoman ini memiliki peluang untuk diterapkan sebagai peningkatan kompetensi konselor untuk bersaing menujukkan kelebihan agar tidak digerus zaman. Konselor yang tidak memiliki identitas di era revolusi industri akan membuat kaburnya pandangan konseli terhadap konseling secara tatap muka. Kajian ini dapat dikembangkan selanjutnya sebagai satu kesatuan pendekatan indigenous baru berbasis karakter Hanoman atau pengembangan karakter tokoh lain dalam kajian budaya lokal. 


\section{DAFTAR PUSTAKA}

Absolon, K. (2010). Indigenous Wholistic Theory: A Knowledge Set for Practice. Journal of First Peoples Child \& Family Review 5(2), 74-87.

Arifin, Samsul \& Zaini, Akhmad. (2014). Dakwah Transformatif Melalui Konseling: Potret Kualitas Kepribadian Konselor Perspektif Konseling At-Tawazun. Jurnal Dakwah, Vol. XV, No. 1. Prodi BKI Fakultas Dakwah IAI Ibrahimy Situbondo Jawa Timur

Baenanda, Listhari. (2019). Mengenal Lebih Jauh Revolusi Industri 4.0. diakses online https://binus.ac.id/knowledge/2019/05/mengenal-lebih-jauh-revolusi-industri-4-0/ pada tanggal 31 Oktober 2019

Corey, Gerald. (2017). Theory and Practice of Counseling and Psychotherapy,

David, Daniel, (2014). Robot-Based Psychotherapy: Concepts Development, State of the Art, and New Directions. International Journal of Cognitive Therapy, 7(2), 192- 210, 2014 International Association for Cognitive Psychotherapy. Diakses online pada tanggal 1 November 2019

Gordon, Winsome. Tanpa Tahun. Counselling. France: UNESCO diakses online www.unesco.org ;education;mebam ;module_2 pada tanggal 1 November 2019

Hidayat, F. (2010). Antropologi Sakral: Revitalisasi Tradisi Metafisik Masyarakat Indigenous Indonesia. Jakarta: IPS Press.

Jones. N. Richard. (2006). Human Relationship Skills: Coaching and Self-Coaching $4^{\text {th }}$ Edition. USA \& Canada: Routledge

Katz,Judith H. (1985). DOI:10.1177/001 1000085134005. The Sosiopolitical Nature of Counseling: Visit http/www.sagepub.com

Kurniasari, Epi. (2016). Tingkat Penguasaan Kompetensi Pedagogik Dan Profesional Guru Bimbingan Dan Konseling. E-Jurnal Bimbingan dan Konseling Universitas Negeri Yogyakarta Edisi 7 Tahun ke-5

Martin, Anna. (2019). The Five Stages of Dealing With Issues. Diakses online http://www.thecounsellorsguide.co.uk/what-counselling-not.html

Pendit, Nyoman S. (2015). Ramayana. Jakarta: Penerbit PT Gramedia Pustaka Surakarta. Tesis tidak diterbitkan

Perinatal Mental Health Project. Basic Counseling Skills: A Guide for Health Workers in Materal Care. Rondebosch: Departement of Psychiatry \& Mental Health

Ristekdikti. (2018). Pengembangan IPTEK dan Pendidikan Tinggi di Era Revolusi Industri 4.0. diakses online https://www.ristekdikti.go.id/kabar/pengembanganiptek-dan-pendidikan-tinggi-di-era-revolusi-industri-4-0-2 pada tanggal 31 Oktober 2019 Tenth Edition. Boston: Cengage Learning

Setyaputri, N. Yuniar. (2017). Karakter Ideal Konselor Multibudaya Berdasarkan Nilai Luhur Semar. Jurnal Kajian Bimbingan dan Konseling, 2(2), 2017, 58-65. Prodi Bimbingan dan Konseling, Fakultas Keguruan dan Ilmu Pendidikan, Universitas Nusantara PGRI

Sharf. S. Richard. (2012). Theories of Psychotherapy and Counseling: Concepts and Cases, 5th Edition. USA: Cengage Learning

Sue, D. W., \& Sue, D. (2008). Counseling The Culturally Diverse: Theory and Practice. USA: John Wiley \& Sons, Inc.

Suryanto, Dwi. (2014). Wayang Terawang "Hanoman". Institut Seni Indonesia

Trilling, B., \& Fadel, C. (2009). 21st Century Skills: Learning for Life in Our Times. San Francisco, CA: John Wiley \& Sons. 